\title{
Traumatic Spondyloptosis: Neurological, Surgical, and Outcome Perspectives in a Tertiary Care Center
}

\author{
Rahul Singh $^{1, \odot}$ Ravi Shankar Prasad ${ }^{1, \odot}$ Ashvamedh Singh ${ }^{1, \odot} \quad$ Kulwant Singh ${ }^{1, \odot}$ Anurag Sahu ${ }^{1, \odot}$ \\ ${ }^{1}$ Department of Neurosurgery, Institute of Medical Sciences- \\ Address for correspondence Ravi Shankar Prasad, MCh, \\ Banaras Hindu University, Varanasi, India \\ Department of Neurosurgery, Institute of Medical \\ Sciences-Banaras Hindu University, Varanasi, India \\ (e-mail: rsprasadbhuhodneurosurgery@gmail.com).
}

Indian J Neurosurg 2022;11:232-240

\begin{abstract}
Objective To evaluate traumatic spondyloptosis cases for neurological, surgical, and outcome perspectives.

Materials and Methods This retrospective study includes 17 patients of spondyloptosis admitted in our department between August 2016 and January 2020. Each patient was evaluated in terms of demographic profile, clinical presentation, duration of injury, mode of injury, associated injuries, level and type of spondyloptosis, spinal cord status, nociceptive and neuropathic pain severity, severity of injury based on International Standards for Neurological Classification of Spinal Cord Injury (ISNCSI) assessment, surgical approaches, complications, and outcome. Unpaired t- test and Chi-square test were used for statistical analysis. Values with $p<0.05$ were considered statistically significant.

Results Fall from height (58.8\%) was the most common mode of injury. Most common level of spondyloptosis was T12-L1 (41.1\%). Sagittal-plane spondyloptosis (76.5\%) were more common than coronal-plane spondyloptosis (23.5\%). Most common associated injury was musculoskeletal (64.7\%). Neurological status of the patient

Keywords

- traumatic spondyloptosis

- neurological status

- spondylolisthesis

- ASIA scale

- spine injury at presentation ( $p=0.0007$ ) was significantly associated with outcome after 3 months of surgery/conservative management. Residual listhesis was present in $53.3 \%$ of patients postoperatively. Postoperative nociceptive pain $(p=0.0171)$ and neuropathic pain (0.0329) were significantly associated with residual listhesis. Duration of injury $(p=0.0228)$ was also significantly associated with postoperative residual listhesis.

Conclusion Complete reduction of spondyloptosis should be the goal of surgery. Overall prognosis of spinal cord injury $(\mathrm{SCl})$ due to traumatic spondyloptosis is poor.
\end{abstract}

\section{Introduction}

Spondyloptosis is the most severe form of spondylolisthesis, characterized by complete subluxation (> 100\%) of a vertebral body with respect to another vertebra. This complete subluxation may occur in either coronal or sagittal planes ( - Figs. 1 and 2). ${ }^{1}$ It can be degenerative or traumatic. Traumatic spondyloptosis results from high-energy trauma causing flexion-rotation stress or shearing force, which causes disruption of facets and ligaments of spine. In coronal spondyloptosis ( - Fig. 2), subluxated vertebral bodies lie in coronal plane and is also called lateraloptosis. ${ }^{2}$ In Denis classification, traumatic spondyloptosis lies in fracture dislocation category $^{3}$ and is a very unstable injury. X-ray of the involved
DOI https://doi.org/ $10.1055 / s-0041-1726608$ ISSN 2277-954X
(C)2022. Neurological Surgeons' Society of India.

This is an open access article published by Thieme under the terms of the Creative Commons Attribution-NonDerivative-NonCommercial-License, permitting copying and reproduction so long as the original work is given appropriate credit. Contents may not be used for commercial purposes, or adapted, remixed, transformed or built upon. (https://creativecommons.org/licenses/by-nc-nd/4.0/). Thieme Medical and Scientific Publishers Pvt. Ltd. A-12, 2nd Floor, Sector 2, Noida-201301 UP, India 
region is sufficient to distinguish a case of spondyloptosis. However, noncontrast CT and MRI of the involved segments better delineate the displacement and extent of spinal cord injury (SCI). The most common location of traumatic spondyloptosis is thoracolumbar junction (T10-L2) due to transition between relatively fixed thoracic spine and mobile lumbar segments of spine. ${ }^{4}$ Since it is associated with either cord transaction or there is severe cord damage, it is always associated with neural deficit. In $80 \%$ of cases, spondyloptosis is associated with complete neurological deficit. ${ }^{5}$ Due to complete neurodeficit associated with this type of injury, the prognosis is poor and the treatment is aimed at rehabilitation rather than the neurological improvement. These injuries are severely unstable, these should not be treated conservatively, because conservative treatment can lead to increased complications related to being bedridden for long; further, nonsurgical treatment may cause future spinal deformity, continuous back pain, and delayed rehabilitation. ${ }^{6}$ Surgical treatment with reduction and rigid stabilization is advisable for such complete dislocation in order to achieve alignment and early rehabilitation. The surgery can be done via anterior, posterior, or combined approach. ${ }^{6}$ The posterior approach is most commonly used and has shown good success and fewer complications. ${ }^{5}$ Surgical reduction of spondyloptosis is quite challenging. In this study, we aim to evaluate traumatic spondyloptosis cases for neurological, surgical and outcome perspectives with respect to ambulation, postoperative pain, degree of reduction following surgery and complications of surgery.

\section{Materials and Methods}

This retrospective cohort study includes cohort of 17 patients of spondyloptosis who underwent surgery or managed conservatively in our department between 1 August 2016 and 31 January 2020. Traumatic spondyloptosis on CT scan was the inclusion criteria in the study.

This is a retrospective cohort study in two phases: a cross-sectional phase where the patients included in the sample were evaluated for the following described variables and a follow-up phase at hospital discharge and at subsequent OPD visits by the patient. Each patient was evaluated in terms of demographic profile, clinical presentation, duration of injury, mode of injury, associated injuries, level of spondyloptosis, type of spondyloptosis, spinal cord status based on CT and MRI, pain severity based on numeric rating scale (NRS) ${ }^{7}$ for nociceptive pain (due to musculoskeletal or visceral injury), and neuropathic pain scale (NPS) ${ }^{8}$ at presentation.

The NRS consists of a numeric version of the visual analog scale (VAS). We categorized pain screening NRS scores as mild (1-3), moderate (4-6), or severe (7-10) and NPS scores as mild (0-30), moderate (30-60), or severe (60-100), depending upon severity.

Patients were also evaluated for severity of injury, based on neurological status and International Standards for Neurological Classification of Spinal Cord Injury (ISNCSI) assessment. ${ }^{9}$ Management, surgical approaches, complications, and outcomes (ambulatory/nonambulatory) were analyzed. Residual listhesis and its relationship with postoperative pain and duration of injury along with outcome after 3 months of surgery were also evaluated.

All patients underwent a CT scan as well as MRI scan of the affected segment of spine to assess the bony injury pattern and document the cord and neural injury. Prior consent for surgery from the patient was taken in each case. We used posterior approach in 13 patients of thoracic, thoracolumbar, lumbar, and lumbosacral level spondyloptosis. We performed a 4-level fixation ( 2 above and 2 below the affected vertebra) using titanium pedicle screws and a titanium rod in these patients. In two cases of cervical spondyloptosis, we did a $360^{\circ}$ fixation. All patients were discharged on home-based rehabilitation training consisting of active and passive muscle stretching and exercises, bladder and bowel care, back care, and psychological support of family members.

The data was summarized using medians/mean, counts, and percentages. Differences of significance in continuous variables and categorical variables were evaluated using the unpaired t- test and Chi-square test, respectively. Values with $p<0.05$ was taken statistically significant. Statistical tests were done using GraphPad Prism version 8.3.0 software.

\section{Results}

A total of 412 patients of traumatic spine injury were operated in our department over the period of 4 years, 2016 to 2020. We had a total of 17 patients of spondyloptosis, out of which 15 (3.64\%) were operated during this period. In this study, the mean age was 34.5 years, ranging from 15 to 48 years. Most of the patients were males (70.6\%) with male to female ratio of $2.4: 1$. Fall from height $(58.8 \%)$ followed by fall of object over back (23.5\%) were the most common modes of injury causing spondyloptosis. The most common associated injury was musculoskeletal (64.7\%) followed by abdominal visceral injury (29.4\%), head injury (23.5\%) and thoracic injury (23.5\%) (-Table 1). Thoracic injuries were managed by intercostal drainage (ICD) and musculoskeletal injuries in accordance to type of injury. Both head injury and abdominal visceral injuries were managed conservatively. The most common level of traumatic spondyloptosis was T12L1 (41.1\%) followed by T11-T12 (11.8\%) and L1-L2 (11.8\%). Sagittal-plane spondyloptosis (76.5\%) was more common than coronal-plane spondyloptosis (23.5\%) (- Table 1). On NRS of nociceptive pain, most of the patients were having severe $(58.8 \%)$ and moderate $(23.5 \%)$ pain at presentation (-Table 1). On pain severity of neuropathic pain (NPS), most patients were having moderate $(76.5 \%)$ severity at admission (-Table 1).

Patient's injury profile, management and outcome of 17 patients of traumatic spondyloptosis in this study is summarized in - Table 2. Neurologically, most of the patients were having American Spinal Injury Association (ASIA)-A status $(14,82.3 \%)$. There was 1 patient each in ASIA-C and ASIA-B and 1 patient was neurologically intact (-Table 2). Spinal cord transection $(12,70.6 \%)$ and dural injury (13, 76.5\%) 
Table 1 Demographic profile, mode of injury, associated injury and level and type of traumatic spondyloptosis $(n=17)$

\begin{tabular}{|c|c|c|}
\hline Patient characteristics & $\begin{array}{l}\text { Number of } \\
\text { patients/ } \\
\text { value }\end{array}$ & Percentage \\
\hline \multicolumn{3}{|l|}{ Age } \\
\hline Mean & 34.5 years & \\
\hline Range & $15-48$ years & \\
\hline \multicolumn{3}{|l|}{ Sex } \\
\hline Male & 12 & 70.6 \\
\hline Females & 5 & 29.4 \\
\hline \multicolumn{3}{|l|}{ Mode of injury } \\
\hline Fall from height & 10 & 58.8 \\
\hline Fall of object over back & 4 & 23.5 \\
\hline Road traffic accident & 3 & 17.7 \\
\hline \multicolumn{3}{|l|}{ Associated injuries } \\
\hline Head injury & 4 & 23.5 \\
\hline Maxillofacial injury & 3 & 17.6 \\
\hline Musculoskeletal injury & 11 & 64.7 \\
\hline $\begin{array}{l}\text { Thoracic injury (hemothorax/ } \\
\text { pneumothorax) }\end{array}$ & 4 & 23.5 \\
\hline Abdominal visceral injury & 5 & 29.4 \\
\hline \multicolumn{3}{|l|}{ Level of spondyloptosis } \\
\hline $\mathrm{C} 6-\mathrm{C} 7$ & 1 & 5.9 \\
\hline C7-T1 & 1 & 5.9 \\
\hline T5-T6 & 1 & 5.9 \\
\hline T12-L1 & 7 & 41.1 \\
\hline T8-T9 & 1 & 5.9 \\
\hline $\mathrm{T} 11-\mathrm{T} 12$ & 2 & 11.8 \\
\hline $\mathrm{L} 1-\mathrm{L} 2$ & 2 & 11.8 \\
\hline L4-L5 & 1 & 5.9 \\
\hline L5-S1 & 1 & 5.9 \\
\hline \multicolumn{3}{|l|}{ Type of spondyloptosis } \\
\hline Sagittal-plane spondyloptosis & 13 & 76.5 \\
\hline Coronal-plane spondyloptosis & 4 & 23.5 \\
\hline \multicolumn{3}{|l|}{$\begin{array}{l}\text { Pain severity scale (NRS) of } \\
\text { nociceptive pain at admission }\end{array}$} \\
\hline None (0) & 2 & 11.8 \\
\hline Mild (1-3) & 1 & 5.9 \\
\hline Moderate (4-6) & 4 & 23.5 \\
\hline Severe $(7-10)$ & 10 & 58.8 \\
\hline \multicolumn{3}{|l|}{$\begin{array}{l}\text { Pain severity of neuropathic pain } \\
\text { at admission }\end{array}$} \\
\hline Mild $(0-30)$ & 2 & 11.8 \\
\hline Moderate (30-60) & 13 & 76.5 \\
\hline Severe $(60-100)$ & 2 & 11.8 \\
\hline
\end{tabular}

Abbreviation: NPS, neuropathic pain scale.

was commonly observed ( - Table 2 ). Eight patients presented within 24 hours, two patients between 24 to 72 hours, and five patients between 72 hours to 1 month. Two patients presented after 1 month of injury and 1 of them was operated for kyphotic deformity (-Table 3 ).

Out of 17 , fifteen patients (88.2\%) were operated for spondyloptosis, and conservative management of two patients was done. Of these two, one patient did not give consent for surgery and the other who presented after 3 months of injury had fixed deformity and was neurologically ASIA-C and so was managed conservatively. Posterior approach was used in most of the cases (93.3\%) and combined posterior and anterior approach was used in one each of C7-T1 and C6-7 spondyloptosis ( - Table 2 ).

Postoperatively, deep vein thrombosis (DVT) developed in 2 patients, bed sore in 3 patients, pulmonary complications in 2 patients, and wound infection in one patient. Two patients developed postoperative cerebrospinal fluid (CSF) leak that resolved spontaneously on conservative management. There were 2 mortalities in this study group due to pulmonary complications and DVT ( - Table 2 ).

In $15(88.2 \%)$ patients, there was no improvement in the neurological status with respect to ambulation. Two patients (11.8\%) showed improvement and were able to ambulate with support ( $\mathbf{- T a b l e ~} \mathbf{3}$ ).

Neurological status of the patient at presentation ( $p=$ 0.0007 ) was significantly associated with outcome after 3 months of surgery/conservative management (- Table 3 ). No significant difference was observed in age, sex, and injury to surgery time for outcome prediction ( - Table 3 ).

Residual listhesis was present in $53.3 \%$ of patients postoperatively. Postoperative nociceptive pain $(p=0.0171)$ and neuropathic pain $(0.0329)$ were significantly associated with residual listhesis ( Table 4 ). Duration of injury ( $p=0.0228$ ) was also significantly associated with postoperative residual listhesis in the study cohort who underwent surgery (-Table 4; Fig. 3 ).

The mean duration of hospital stay was 20 days (range 8-36 days). All of the patients were discharged from the hospital for home-based rehabilitation. The mean duration of the follow-up period was 2.1 years (range 3-38 months). In total, 2 patients (11.8\%) died during the follow-up period, mainly from complications resulting from bed sores, DVT, and pulmonary affection.

\section{Discussion}

High-energy trauma frequently results in spine fractures of various grades. Spondyloptosis is the most severe form. Spondyloptosis usually results from high-velocity injury. ${ }^{10}$ In this study, incidence of spondyloptosis cases among operated cases of traumatic spine injury was 3.64\% over the period of 4 years.

Various case series have reported greater incidence of traumatic spondyloptosis among the young productive population (2nd to 4 th decades) and male predominance. ${ }^{4,11}$ In this study, age of patients ranged from 15 to 48 years, and most of them were young. Males (70.6\%) were more in number. Fall from height (58.8\%) followed by fall of object over back (23.5\%) were the most common modes of injury causing spondyloptosis in our study. In various series, fall from height 
Table 2 Patient profile and characteristics of traumatic spondyloptosis

\begin{tabular}{|c|c|c|c|c|c|c|c|c|c|}
\hline $\begin{array}{l}\text { S. } \\
\text { no }\end{array}$ & $\begin{array}{l}\text { Level of } \\
\text { traumatic } \\
\text { spondyloptosis }\end{array}$ & MOI & $\begin{array}{l}\text { Associated } \\
\text { injury }\end{array}$ & $\begin{array}{l}\text { Neurological } \\
\text { status at } \\
\text { admission }\end{array}$ & $\begin{array}{l}\text { Spinal cord } \\
\text { status }\end{array}$ & $\begin{array}{l}\text { Duration } \\
\text { of injury }\end{array}$ & Management & Complications & Outcome \\
\hline 1 & C6-C7 & RTA & $\begin{array}{l}\text { Maxillofacial } \\
\text { injury }\end{array}$ & ASIA A & Transected & 3.5 days & $360^{\circ}$ fixation & \begin{tabular}{|l|} 
Bed sore + \\
pulmonary \\
complications
\end{tabular} & Death \\
\hline 2 & C7-T1 & FFH & $\begin{array}{l}\text { Head injury }+ \\
\text { clavicle fracture }\end{array}$ & ASIA A & $\begin{array}{l}\text { Transected } \\
\text { Dural tear + }\end{array}$ & 4 days & $360^{\circ}$ fixation & - & No improvement \\
\hline 3 & T5-T6 & FOB & Hemothorax & $\begin{array}{l}\text { No neurologi- } \\
\text { cal deficit }\end{array}$ & Intact & 17 hours & 4-level fixation & - & $\begin{array}{l}\text { Recovered } \\
\text { ambulation }\end{array}$ \\
\hline 4 & T8-T9 & FFH & $\begin{array}{l}\text { Pneumo- } \\
\text { hemothorax }+ \\
\text { femur fracture }\end{array}$ & ASIAC & - & \begin{tabular}{|l|}
3.2 \\
months
\end{tabular} & Conservative & - & $\begin{array}{l}\text { Recovered } \\
\text { ambulation }\end{array}$ \\
\hline 5 & T11-T12 & FFH & $\begin{array}{l}\text { Grade II splenic } \\
\text { injury + radius } \\
\text { fracture }\end{array}$ & ASIA A & $\begin{array}{l}\text { Transected } \\
\text { Dural tear }+\end{array}$ & 7 days & 4-level fixation & $\begin{array}{l}\text { CSF leak } \\
+ \text { wound } \\
\text { infection }\end{array}$ & No improvement \\
\hline 6 & T11-T12 & FOB & Hemothorax & ASIA A & $\begin{array}{l}\text { Transected } \\
\text { Dural tear }+\end{array}$ & 17 hours & 4-level fixation & - & No improvement \\
\hline 7 & T12-L1 & FFH & \begin{tabular}{|l|} 
Grade III liver \\
injury with \\
hemoperitoneum
\end{tabular} & ASIA A & $\begin{array}{l}\text { Transected } \\
\text { Dural tear }+\end{array}$ & 6 hours & 4-level fixation & CSF leak & No improvement \\
\hline 8 & T12-L1 & FOB & Rib fracture & ASIA A & $\begin{array}{l}\text { Transected } \\
\text { Dural tear + }\end{array}$ & 10 days & 4-level fixation & - & No improvement \\
\hline 9 & T12-L1 & RTA & $\begin{array}{l}\text { Tibia shaft } \\
\text { fracture with } \\
\text { maxillofacial } \\
\text { injury }\end{array}$ & ASIA A & \begin{tabular}{|l|} 
Transected \\
Dural tear +
\end{tabular} & $\begin{array}{l}1.5 \\
\text { months }\end{array}$ & 4-level fixation & $\begin{array}{l}\text { DVT + bed sore } \\
+ \text { pulmonary } \\
\text { complications }\end{array}$ & Death \\
\hline 10 & T12-L1 & $\mathrm{FFH}$ & $\begin{array}{l}\text { Head injury + } \\
\text { Grade I splenic } \\
\text { injury with } \\
\text { humerus fracture }\end{array}$ & ASIA A & - & 22 hours & $\begin{array}{l}\text { Not } \\
\text { Consented for } \\
\text { surgery }\end{array}$ & DVT & No improvement \\
\hline 11 & T12-L1 & FFH & Hemothorax & ASIA A & $\begin{array}{l}\text { Transected } \\
\text { Dural tear + }\end{array}$ & 36 hours & 4-level fixation & Bed sore & No improvement \\
\hline 12 & T12-L1 & $\mathrm{FFH}$ & $\begin{array}{l}\text { Grade I liver } \\
\text { injury + femur } \\
\text { fracture }\end{array}$ & ASIA A & $\begin{array}{l}\text { Transected } \\
\text { Dural tear }+\end{array}$ & 4 days & 4-level fixation & - & No improvement \\
\hline 13 & T12-L1 & RTA & $\begin{array}{l}\text { Grade III splenic } \\
\text { injury }\end{array}$ & ASIA A & $\begin{array}{l}\text { Transected } \\
\text { Dural tear + }\end{array}$ & 47 hours & 4-level fixation & - & No improvement \\
\hline 14 & L1-L2 & FFH & $\begin{array}{l}\text { Maxillofacial } \\
\text { injury + head } \\
\text { injury + femur } \\
\text { fracture }\end{array}$ & ASIA A & $\begin{array}{l}\text { Transected } \\
\text { Dural tear }+\end{array}$ & 6 hours & 4-level fixation & - & No improvement \\
\hline 15 & L1-L2 & $\mathrm{FFH}$ & Pelvis fracture & ASIA A & $\begin{array}{l}\text { Transected } \\
\text { Dural tear + }\end{array}$ & 22 hours & 4-level fixation & DVT & No improvement \\
\hline 16 & L4-L5 & FOB & Femur fracture & ASIA B & $\begin{array}{l}\text { Contused }+ \\
\text { dural tear }\end{array}$ & 17 hours & 4-level fixation & - & $\begin{array}{l}\text { Recovered bladder/ } \\
\text { bowel function }\end{array}$ \\
\hline 17 & L5-S1 & FFH & $\begin{array}{l}\text { Pelvis fracture + } \\
\text { head injury }\end{array}$ & ASIA A & $\begin{array}{l}\text { Transected } \\
\text { Dural tear + }\end{array}$ & 13 hours & $\begin{array}{l}\text { 4-level } \\
\text { fixation }\end{array}$ & - & No improvement \\
\hline
\end{tabular}

Abbreviations: ASIA, American Spinal Injury Association; DVT, deep vein thrombosis.

and motor vehicle accidents have been reported to be the most common modes of injury causing spondyloptosis., , $^{2,11,12}$

The most common associated injury were musculoskeletal, abdominal visceral injury, head injury, and thoracic injury. The management of traumatic spondyloptosis is guided by associated injuries. First and foremost, life-threatening associated injuries should be addressed and a holistic approach for polytrauma must be enacted. Associated injuries are common, as traumatic spondyloptosis are indicative of high-energy trauma, which may also affect other parts of the body.

In our study, we found that most common level of traumatic spondyloptosis was T12-L1 level (41.1\%) followed by T11-T12 \& L1-L2 levels (11.8\% each). Thus, located at the thoracolumbar junction. Studies have reported thoracolumbar junction (T10-L2) as the most common location of traumatic spondyloptosis, ${ }^{4,11}$ which is similar to our findings. Cause of higher incidence of spondyloptosis at this location 
Table 3 Outcome analysis after 3 months of surgery/conservative management

\begin{tabular}{|c|c|c|c|}
\hline Patient characteristics & No improvement $(n=15)$ & $\begin{array}{l}\text { Recovered ambulation } \\
(n=2)\end{array}$ & $p$-Value \\
\hline Age (years) & & & \multirow[t]{3}{*}{0.1103} \\
\hline$<30$ & 6 & 2 & \\
\hline$>30$ & 9 & 0 & \\
\hline Sex & & & \multirow[t]{3}{*}{0.3311} \\
\hline Male & 10 & 2 & \\
\hline Female & 5 & 0 & \\
\hline Neurological status at presentation & & & \multirow[t]{5}{*}{$0.0007^{a}$} \\
\hline ASIA-A (14) & 14 & 0 & \\
\hline ASIA-C (1) & 0 & 1 & \\
\hline ASIA-B (1) & 1 & 0 & \\
\hline Neurologically intact (1) & 0 & 1 & \\
\hline Injury to surgery time $(n=15)$ & & & \multirow[t]{5}{*}{0.3539} \\
\hline$<24$ hours $(7)$ & 6 & 1 & \\
\hline $24-72$ hours $(2)$ & 1 & 1 & \\
\hline $72-1$ month (5) & 5 & 0 & \\
\hline$>1$ month (1) & 1 & 0 & \\
\hline
\end{tabular}

Abbreviation: ASIA, American Spinal Injury Association.

aStatistically significant $(p<0.05)$.

Table 4 Relation of postoperative residual listhesis with postoperative pain and time of surgery

\begin{tabular}{|c|c|c|c|}
\hline Patient characteristics & $\begin{array}{l}\text { Residual listhesis } \\
\text { present }(n=8)\end{array}$ & $\begin{array}{l}\text { Residual listhesis absent } \\
(n=7)\end{array}$ & $p$-Value \\
\hline Postoperative nociceptive pain (NRS) & & & \multirow[t]{5}{*}{$0.0171^{\mathrm{a}}$} \\
\hline None $(0)$ & 0 & 4 & \\
\hline Mild (1-3) & 2 & 3 & \\
\hline Moderate (4-6) & 5 & 0 & \\
\hline Severity $(7-10)$ & 1 & 0 & \\
\hline Follow-up neuropathic pain & & & \multirow[t]{4}{*}{$0.0329^{a}$} \\
\hline Mild $(0-30)$ & 1 & 5 & \\
\hline Moderate (30-60) & 3 & 2 & \\
\hline Severe $(60-100)$ & 4 & 0 & \\
\hline Injury to surgery time & & & \multirow[t]{5}{*}{$0.0228^{\mathrm{a}}$} \\
\hline$<24$ hours & 1 & 6 & \\
\hline $24-72$ hours & 1 & 1 & \\
\hline $72-1$ month & 5 & 0 & \\
\hline$>1$ month & 1 & 0 & \\
\hline
\end{tabular}

Abbreviation: NRS, numeric rating scale.

aStatistically significant $(p<0.05)$.

may be due to the fact that there is a relatively fixed thoracic spine and mobile lumbar segments of spine ${ }^{4}$ in this region.

Cervical, lower lumbar, and lumbosacral traumatic spondyloptosis were few in this study as compared to that at thoracolumbar junction. Studies have shown subaxial cervical spine C7-T1 as the most common location of cervical spondyloptosis. ${ }^{12}$ Among lower lumbar and lumbosacral spondyloptosis, studies have reported lumbosacral junction as the most common site. ${ }^{13}$ Although cervical traumatic spondyloptosis is less common in our study, but it is the most neurologically devastating injury with resultant quadriparesis.

In this study, sagittal-plane spondyloptosis (76.5\%) was more common than coronal-plane spondyloptosis (23.5\%). In various case series, similar findings were present. ${ }^{4,11}$

Neuropathic pain following SCI results in poor rehabilitation outcomes. ${ }^{14,15}$ Around half to two-thirds of all people 
with SCI have neuropathic pain. ${ }^{16}$ Studies have found that people with tetraplegia were prone to report below-level neuropathic pain than people with paraplegia. ${ }^{17}$ In this study, we used NPS for pain severity assessment at presentation and follow-up. Most of the patients were having moderate (76.5\%) neuropathic pain at presentation and mild neuropathic pain (35.3\%) at follow-up. There is paucity of literature with regard to neuropathic pain severity assessment in spondyloptosis patients. In our study, most patients were having severe nociceptive pain (58.8\%) at admission and moderate (29.4\%) at postoperative period. It is very important to distinguish the pain complained by the patient into nociceptive and neuropathic because both entities require different management strategies. The use of simple analgesics, nonsteroidal anti-inflammatory drugs (NSAIDs), and opioids are frequently reported for treatment of patients with musculoskeletal pain after $\mathrm{SCl} .{ }^{18}$ Neuropathic pain relief in patients with SCI requires a broad approach. Medications (anticonvulsants, antidepressants, opioids, and antispasticity medications), surgical interventions, the use of modalities, and psychotherapy are included in this approach. ${ }^{19}$

Spondyloptosis is associated with complete neurological deficit in most of the cases. ${ }^{5}$ In our study, most of the patients were having ASIA-A status (82.3\%). However, various case reports are there with different level spondyloptosis presenting with intact or remaining neurological functions., ${ }^{7,20-26}$ There was 1 patient each in ASIA-C and ASIA-B and 1 patient was neurologically intact in our study cohort.

Spinal cord transection and dural injury was present in most of the cases intraoperatively in our study. Severe

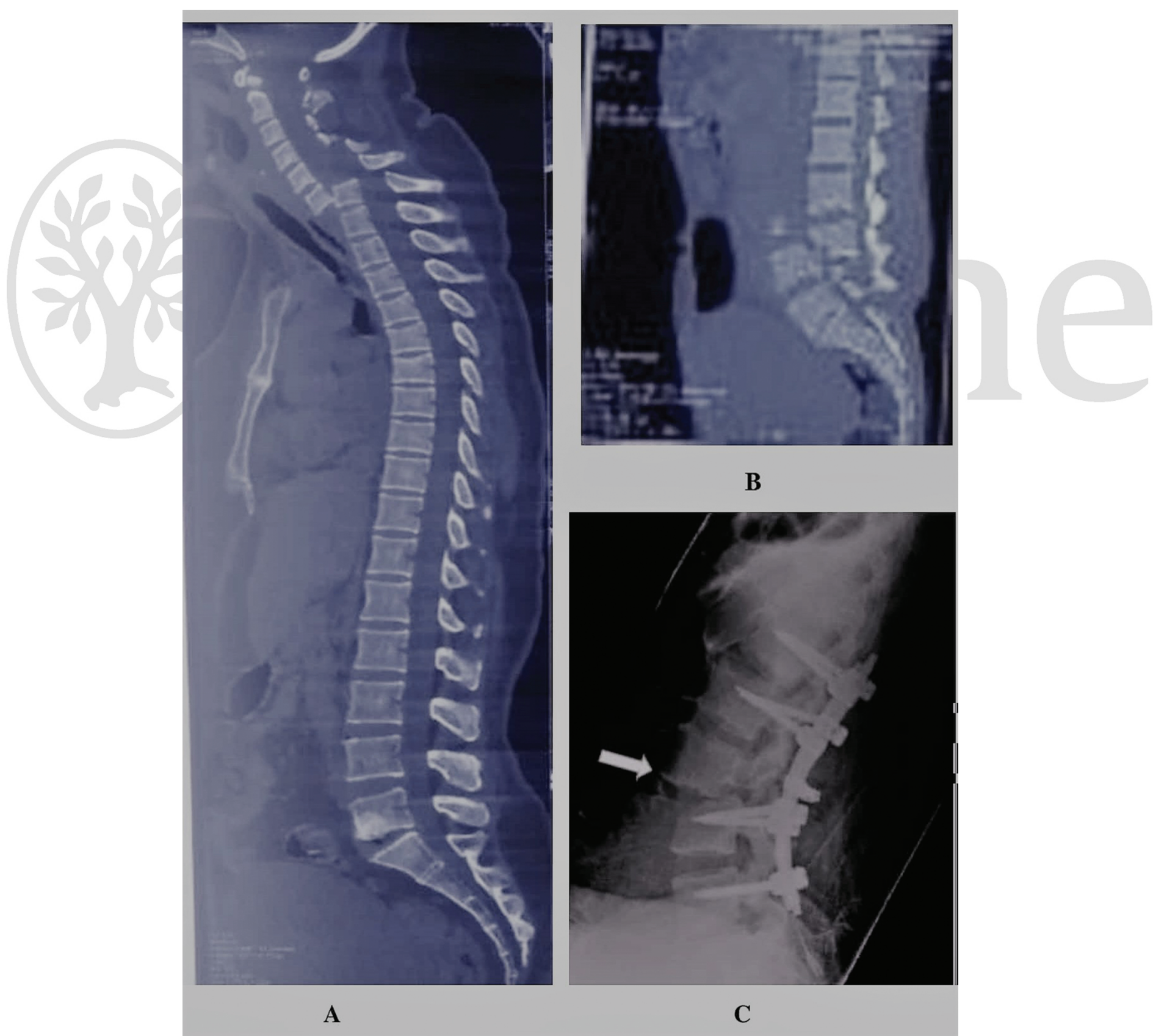

Fig. 1 Sagittal spondyloptosis (A-C6/C7 spondyloptosis, B-L3/L4 spondyloptosis, C-arrow showing residual listhesis after reduction and fixation). 


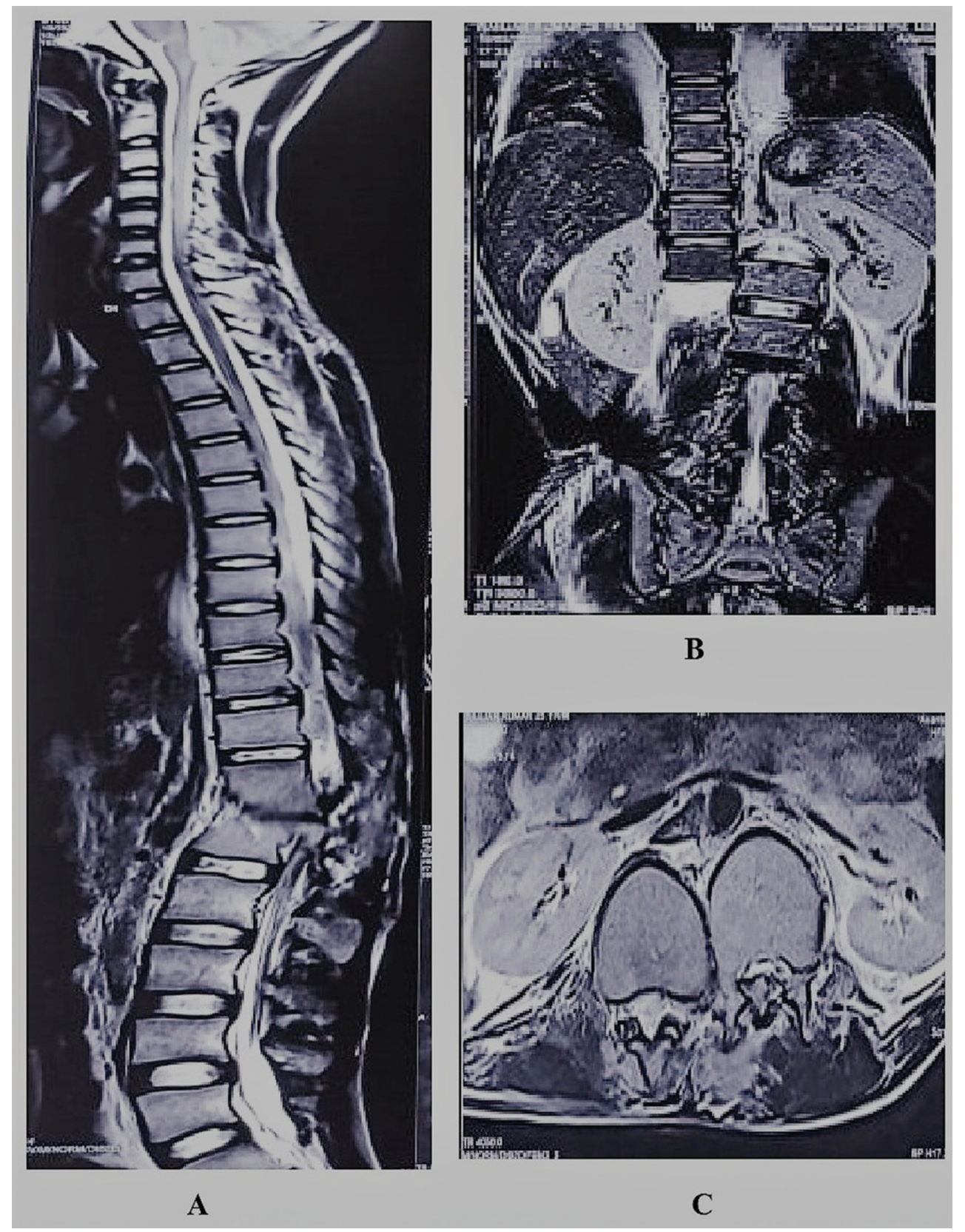

Fig. 2 Coronal spondyloptosis D12-L1 level (A-sagittal view, B-coronal view and C-axial view).

dislocation seen in spondyloptosis puts a shearing force on dura and spinal cord, leading to such injury. Mechanism of injury described for these injuries is due to high-impact trauma, causing axial compression and shearing simultaneously, leading to fractured facet joints and all ligament rupture which, in turn, leads to complete dislocation of spine. Hence, these injuries involve disruption of all the three spinal column, and they are inherently severely unstable injuries. ${ }^{6}$

Due to complete neurodeficit associated with this type of injury, the prognosis is poor and the treatment is aimed for rehabilitation rather than the neurological improvement. Surgical treatment with reduction and rigid stabilization is advisable for such complete dislocation in order to achieve alignment and early rehabilitation. The surgery can be done via anterior, posterior, or combined approach. ${ }^{7,20-26}$ We prefer a 4-level posterior fixation (2 levels above and 2 levels below the lesion) with pedicle screws and a rod in traumatic spondyloptosis involving thoracic, thoracolumbar, lumbar, and lumbosacral region. In patients with cervical traumatic spondyloptosis, we do anterior cervical discectomy and fusion if spinal alignment can be achieved. If not, then posterior reduction and fixation is done (posterior lateral mass fusion with or without laminectomy), that is, $360^{\circ}$ fixation. If the vertebral body of the involved vertebra is damaged, then corpectomy with expandable cage fixation may be required. In this study, we have used posterior approach in most of the cases and combined posterior and anterior approach $\left(360^{\circ}\right)$ in cases of cervical traumatic spondyloptosis. Studies have shown that there are no significant differences between the anterior-only, posterior-only, and $360^{\circ}$ repair groups 


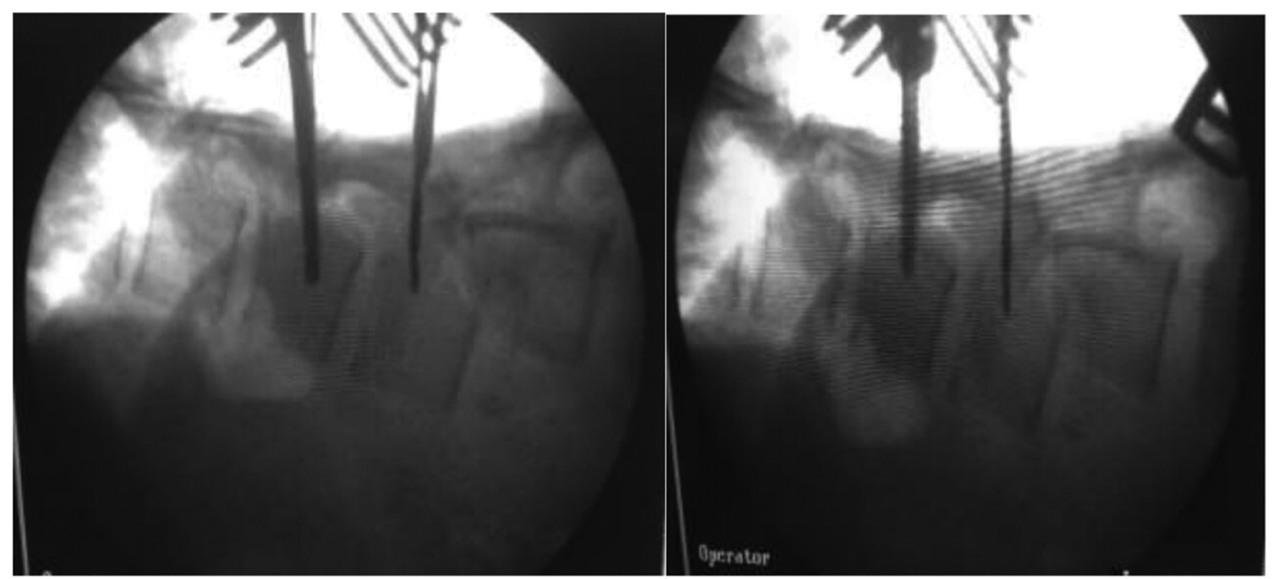

A

B
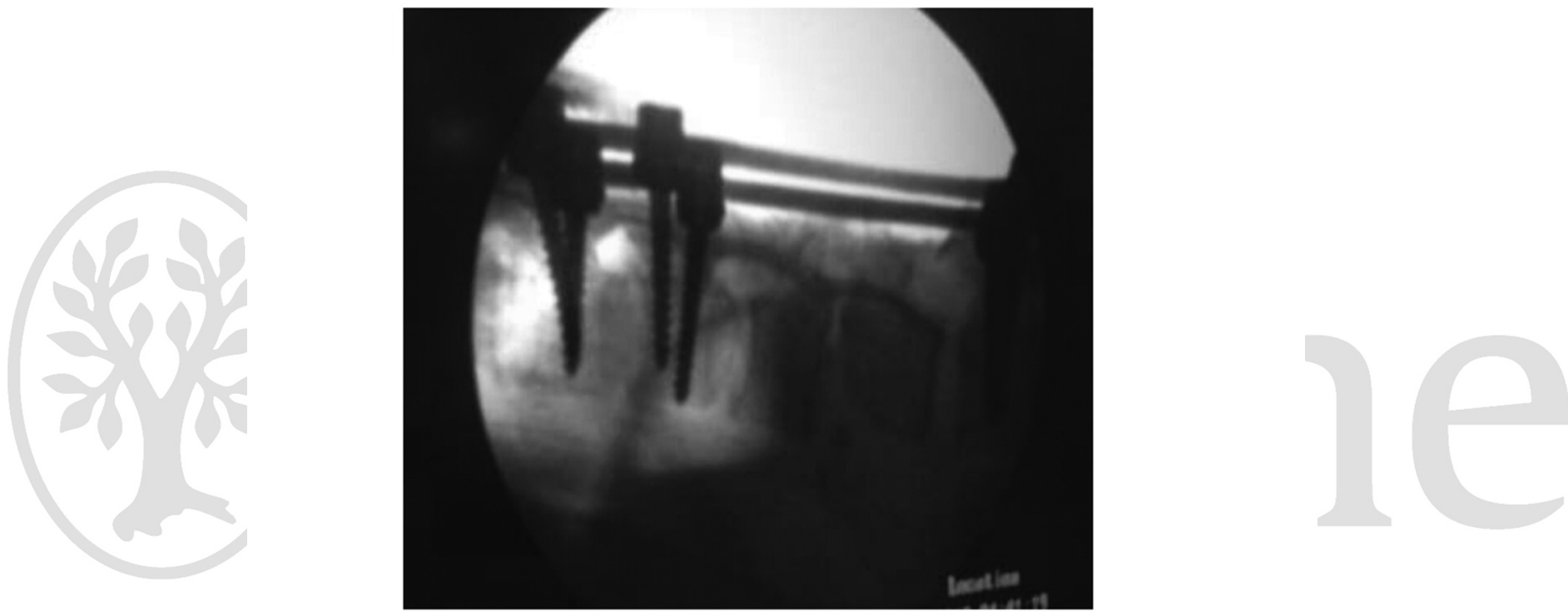

C

Fig. 3 Intraoperative C-arm instrumentation showing spondyloptosis reduction and fixation.

regarding immediate postoperative ASIA grade and ASIA grade at the end of the follow-up period. ${ }^{27}$

DVT, wound infection, hematoma formation, bed sore, and CSF leak were main postoperative complications in this study group. CSF leak in our study resolved spontaneously on conservative management. In reported series, similar complications were evident. ${ }^{4,11}$ Spinal cord transection and dural injury was commonly observed intraoperatively in most of the cases irrespective of level of traumatic spondyloptosis. We prefer direct suture repair for dural tear followed by Valsalva maneuver to test the suturing. Augmented closure by means of fat, muscle tissue or fascial graft is indicated when the dural defect is too large to be directly repaired. Fibrin glue is used when we have possibility of CSF leak after dural closure. Various authors prefer similar methods in their studies. $^{28,29}$

In this study, neurological status of the patient was significantly associated with outcome after 3 months of surgery/conservative management. This can be attributed to severity of SCI. Greater the extent of SCI, more is the neurological deficit and poorer recovery. However, no association was found between injury to surgery time and outcome. There is paucity of literature in this regard in cases of spondyloptosis.

While operating traumatic spondyloptosis at any spinal level, it is very difficult to achieve complete reduction of listhesis, especially when the injury is long-standing and fusion with adjacent structures had occurred. While providing traction for cervical region to achieve alignment, it is much easier than that for other segments. We prefer to reduce the listhesis as complete as possible. We accept the residual listhesis of less than or equal to grade 1 , if despite maximum efforts and maneuvers complete alignment is lacking. Residual listhesis in our study was present in about half of our patients postoperatively. Postoperative nociceptive pain and neuropathic pain at follow-up were significantly associated with residual listhesis. This may be attributed to nerve compression due to residual listhesis. Studies have shown that residual stenosis, arachnoiditis, and psychological effects may cause neuropathic pain after spinal surgery. ${ }^{30-32}$ 
Duration of injury was also significantly associated with postoperative residual listhesis in the study cohort. More the duration, more is the fibrosis and fixation of deformity, leading to difficulty in achieving reduction.

\section{Conclusion}

Traumatic spondyloptosis is a rare entity. Using modern spinal stabilization techniques, anatomical alignment may be reliably obtained in these injuries. Early surgery is advocated for better result in terms of reduction and better relief of pain. Complete reduction of spondyloptosis should be the goal of surgery. Overall prognosis of spinal cord injury due to traumatic spondyloptosis is poor.

\section{Conflicts of Interest}

None declared.

\section{References}

1 Chandrashekhara SH, Kumar A, Gamanagatti S, et al. Unusual traumatic spondyloptosis causing complete transection of spinal cord. Int Orthop 2011;35(11):1671-1675

2 Garg M, Kumar A, Sawarkar DP, et al. Traumatic Lateral spondyloptosis: case series. World Neurosurg 2018;113:e166-e171

3 Denis $F$. The three column spine and its significance in the classification of acute thoracolumbar spinal injuries. Spine 1983; $8(8): 817-831$

4 Mishra A, Agrawal D, Gupta D, Sinha S, Satyarthee GD, Singh PK. Traumatic spondyloptosis: a series of 20 patients. J Neurosurg Spine 2015;22(6):647-652

5 Shapiro S, Abel T, Rodgers RB. Traumatic thoracic spinal fracture dislocation with minimal or no cord injury. Report of four cases and review of the literature. J Neurosurg 2002; 96(3, Suppl):333-337

6 Pathak A, Jain M, Tandon S, Verma R. Results of single stage posterior instrumentation in complete traumatic spondyloptosis of thoracolumbar spine. Ortho J MPC. 2018;24(2):61-66

7 Akesen B, Mutlu M, Kara K, Aydınlı U. Traumatic lumbosacral spondyloptosis: a case report and review of the literature. Global Spine J 2014;4(1):59-62

8 Galer BS, Jensen MP. Development and preliminary validation of a pain measure specific to neuropathic pain: the Neuropathic Pain Scale. Neurology 1997;48(2):332-338

9 American Spinal Injury Association, International Standards for Neurological Classifications of Spinal Cord Injury. revised ed. Chicago, Ill: American Spinal Injury Association; 2000:1-23

10 Meneghini RM, DeWald CJ. Traumatic posterior spondyloptosis at the lumbosacral junction. A case report. J Bone Joint Surg Am 2003;85(2):346-350

11 Yadla S, Lebude B, Tender GC, et al. Traumatic spondyloptosis of the thoracolumbar spine.J Neurosurg Spine 2008;9(2):145-151

12 Modi JV, Soman SM, Dalal S. Traumatic cervical spondyloptosis of the subaxial cervical spine: a case series with a literature review and a new classification. Asian Spine J 2016;10(6): 1058-1064
13 Kaplan SS, Wright NM, Yundt KD, Lauryssen C. Adjacent fracture-dislocations of the lumbosacral spine: case report. Neurosurgery 1999;44(5):1134-1137

14 Jensen MP, Chodroff MJ, Dworkin RH. The impact of neuropathic pain on health-related quality of life: review and implications. Neurology 2007;68(15):1178-1182

15 Ullrich PM, Jensen MP, Loeser JD, Cardenas DD. Pain intensity, pain interference and characteristics of spinal cord injury. Spinal Cord 2008;46(6):451-455

16 van Gorp S, Kessels AG, Joosten EA, van Kleef M, Patijn J. Pain prevalence and its determinants after spinal cord injury: a systematic review. Eur J Pain 2015;19(1):5-14

17 Siddall PJ, McClelland JM, Rutkowski SB, Cousins MJ. A longitudinal study of the prevalence and characteristics of pain in the first 5 years following spinal cord injury. Pain 2003; 103(3):249-257

18 Rekand T, Hagen EM, Grønning M. Chronic pain following spinal cord injury. Tidsskr Nor Laegeforen 2012;132(8):974-979

19 Sezer N, Akkuş S, Uğurlu FG. Chronic complications of spinal cord injury. World J Orthop 2015;6(1):24-33

20 Cabrera JP, Yankovic W, Luna F, et al. Traumatic spondyloptosis of L3 with incomplete neurological involvement: a case report. Trauma Case Rep 2019;24:100248. Published 2019 Oct 31

21 Farooque K, Khatri K, Gupta A. Missed traumatic thoracic spondyloptosis with no neurological deficit: a case report and literature review. Trauma Mon 2016;21(1):e19841

22 Mamindla RK, Kumar A, Bhattacharjee S, Sahu BP. A novel case of "ambulatory" cervical spondyloptosis: case report with literature review. Eur Spine J 2014;23(Suppl 2) :161-166

23 Rao PJ, Lu VM, Sergides IG. Traumatic mid-thoracic spondyloptosis without neurological deficit: a case report and review of literature. ANZ J Surg 2018;88(10):1083-1085

24 Tian NF, Mao FM, Xu HZ. Traumatic fracture-dislocation of the lumbar spine. Surgery 2013;153(5):739-740

25 Tumialán LM, Dadashev V, Laborde DV, Gupta SK. Management of traumatic cervical spondyloptosis in a neurologically intact patient: case report. Spine 2009;34(19):E703-E708

26 Xu F, Tian Z, Fu C, et al. Mid-lumbar traumatic spondyloptosis without neurological deficit: A case report and literature review. Medicine (Baltimore) 2020;99(12):e19578

27 Wong KE, Chang PS, Monasky MS, Samuelson RM. Traumatic spondyloptosis of the cervical spine: A case report and discussion of worldwide treatment trends. Surg Neurol Int 2017;8:89

28 Espiritu MT, Rhyne A, Darden BV II. Dural tears in spine surgery. J Am Acad Orthop Surg 2010;18(9):537-545

29 FangZ,Tian R,JiaYT,XuTT, LiuY.Treatment of cerebrospinalfluid leak after spine surgery. Chin J Traumatol 2017;20(2):81-83

30 Baber Z, Erdek MA. Failed back surgery syndrome: current perspectives. J Pain Res 2016;9:979-987

31 Bokov A, Isrelov A, Skorodumov A, Aleynik A, Simonov A, Mlyavykh $S$. An analysis of reasons for failed back surgery syndrome and partial results after different types of surgical lumbar nerve root decompression. Pain Physician 2011; 14(6):545-557

32 Rigoard P, Blond S, David R, Mertens P. Pathophysiological characterisation of back pain generators in failed back surgery syndrome (part B). Neurochirurgie 2015;61(Suppl 1) :S35-S44 